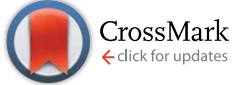

Cite this: RSC Adv., 2015, 5, 4103

\title{
Catalytic acetoxylation of lactic acid to 2-acetoxypropionic acid, en route to acrylic acid $\dagger$
}

\author{
Rolf Beerthuis, ${ }^{a}$ Marta Granollers, ${ }^{b}$ D. Robert Brown, ${ }^{\text {b Horacio J. Salavagione, }}{ }^{c}$ \\ Gadi Rothenberg ${ }^{a}$ and N. Raveendran Shiju ${ }^{\star a}$
}

\begin{abstract}
We present an alternative synthetic route to acrylic acid, starting from the platform chemical lactic acid and using heterogeneous catalysis. To improve selectivity, we designed an indirect dehydration reaction that proceeds via acetoxylation of lactic acid to 2-acetoxypropionic acid. This intermediate can then be pyrolized to acrylic acid. Acetic acid is used both as a reagent and a solvent in the first step, and may be recovered in the subsequent pyrolysis step. We tested a range of solid acid catalysts for the acetoxylation step ( $Y$ zeolites, sulfated zirconia, ion-exchange resins, sulfonated graphene, and various sulfonated silica gels and mixed oxides). Recycling studies were carried out for the most active catalysts. To enable quantitative analysis using gas chromatography we also developed a reliable silylation derivatization method, which is also reported. These results open opportunities for improving the biorenewable production of acrylic acid.
\end{abstract}

Received 19th October 2014 Accepted 20th November 2014

DOI: $10.1039 / c 4 r a 12695 e$

www.rsc.org/advances

\section{Introduction}

Biorenewable production of bulk chemicals receives much attention in academia and industry. It is considered a must for a sustainable society. However, most of today's biorenewable bulk products are based on biotechnological processes. ${ }^{1,2}$ This creates a barrier for the chemical industry, which, being conservative, prefers using known and trusted chemical routes and unit operations. This is well justified from an economic point of view, since moving to new technologies is riskier. ${ }^{3}$ Herein, we investigate the biorenewable production of acrylic acid starting from biosourced lactic acid (LA), yet using a chemocatalytic route. Our results show that this gives a valid and promising pathway for making acrylic acid from biorenewables.

Acrylic acid (AA) is an important bulk chemical. It is a versatile intermediate and monomer used for making superabsorbent polymers (55\%) and various acrylic esters (30\%, see Fig. 1). These are incorporated in many useful products, including diapers and synthetic rubber. In 2012, global acrylic acid production was 4.5 million metric tons, with a growing demand of $4 \%$ per year. ${ }^{4-6}$ It is currently produced through a

\footnotetext{
${ }^{a}$ Van't Hoff Institute for Molecular Sciences, University of Amsterdam, P.O. Box 94157, 1090GD Amsterdam, The Netherlands.E-mail: n.r.shiju@uva.nl; Web: http://hims. uva.nl/hcsc

${ }^{b}$ Department of Chemical Sciences, University of Huddersfield, Huddersfield, HD1 $3 D H, U K$

${ }^{c}$ Departamento de Física de Polímeros, Elastómeros y Aplicaciones Energéticas, Instituto de Ciencia y Tecnología de Polímeros, CSIC, c/Juan de la Cierva, 3, 28006 Madrid, Spain

† Electronic supplementary information (ESI) available: GC-MS, ${ }^{1} \mathrm{H}$ NMR and GC calibration data. See DOI: 10.1039/c4ra12695e
}

two-step gas-phase oxidation of propylene via acrolein. ${ }^{4}$ This energy intensive process depends on petrobased propylene, the cost of which has been volatile recently. ${ }^{7,8}$ Several biotechnological pathways have been proposed as alternatives, but, none of these are currently commercially viable. ${ }^{9}$

One attractive possibility is starting from lactic acid, because it has a C3 carbon skeleton and already contains the external carboxyl group. ${ }^{10}$ Today, LA is produced via fermentation of starch or glucose, with global production of $c a .400$ ktpa in 2012. We expect this to grow further as processes using molasses/ whey waste and lignocellulosic biomass come on stream..$^{11-13}$

Dehydration of LA to acrylic acid was done both in the liquid and vapour phase, using various sulfate ${ }^{\mathbf{1 4}}$ and phosphate based catalysts, ${ }^{15,16}$ inorganic salts ${ }^{17,18}$ and various modified Faujasite zeolites. ${ }^{19-21}$ The best results were reported by Ghantani et al., ${ }^{22,23}$ who obtained $78 \%$ yield at full conversion, converting a lactic acid feed (25 wt $\%$ ) over a calcium pyrophosphate catalyst at $375{ }^{\circ} \mathrm{C}$, with a WHSV of $3 \mathrm{~h}^{-1}$.

Generally, decarboxylation of the carbocation intermediate results in low selectivity. ${ }^{\mathbf{4 2 4 , 2 5}}$ One route that can overcome the problems involved with the direct dehydration of LA is the acetic acid esterification to 2-acetoxypropionic acid (2-APA). Subsequent pyrolysis of 2-APA is straightforward, with over 95\%

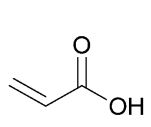

acrylic acid

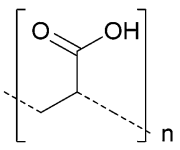

polyacrylic acid

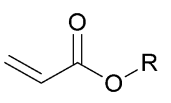

acrylic esters
Fig. 1 Acrylic acid and its major end-products. 
yield. ${ }^{6,26}$ This route was reported previously using homogeneous catalysis. $^{26,27}$ Such catalysts, however, are too expensive for large-scale application. Therefore, we turned to solid catalysts, which are both cheaper and easier to separate. ${ }^{28}$

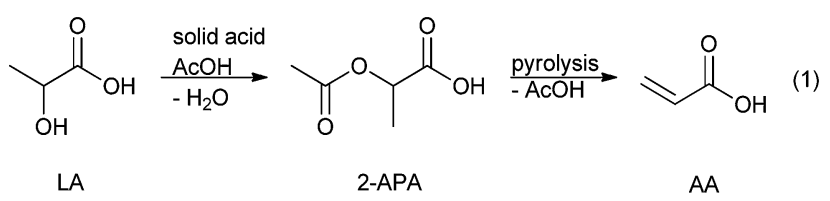

Here, we describe the efficient solid acid catalysed acetoxylation of LA to 2-APA. Subsequent pyrolysis can yield AA in high efficiency, regenerating acetic acid in the process (eqn (1)). The cyclic elimination of $\mathrm{AcOH}$ does not proceed via a carbocation intermediate, increasing the selectivity to acrylic acid. We tested a number of solid acid catalysts (Y zeolites, sulfated zirconia, ion-exchange resins, sulfonated graphene, and various sulfonated silica gels and mixed oxides) and compared those for activity and reusability. Accordingly, the highest activity and selectivity were found for various sulfonic based catalysts. Of those, the ion-exchange resins showed the best recycling results.

\section{Experimental section}

\subsection{Materials and instrumentation}

Gas chromatography (GC) analysis was performed on an Agilent 7820A instrument equipped with a flame ionization detector (FID), an autosampler (G4513A) and a $30 \mathrm{~m} \times 0.32 \mathrm{~mm}$ i.d. VB-1 fused silica capillary column, coated with dimethylpolysiloxane polymer at $3.00 \mu \mathrm{m}$ film thickness (VICI AG International CFSA03032-300B). The carrier gas was helium held at $77 \mathrm{kPa}$ head pressure with a split ratio of $20: 1$. The split/splitless injection port was held at $200{ }^{\circ} \mathrm{C}$ and the flame ionization detector at $250{ }^{\circ} \mathrm{C}$. For the analysis method, the GC oven was programmed to start at $90{ }^{\circ} \mathrm{C}$ for $2 \mathrm{~min}$, then to reach $200{ }^{\circ} \mathrm{C}$ at $10^{\circ} \mathrm{C} \mathrm{min}^{-1}$, followed by an increase in temperature to $280{ }^{\circ} \mathrm{C}$ at a rate of $30{ }^{\circ} \mathrm{C} \mathrm{min}^{-1}$, followed by an isotherm of $5 \mathrm{~min}$. Under these conditions, the retention times were $5.7 \mathrm{~min}$ for silylated acrylic acid (AA-TMS), $10.2 \mathrm{~min}$ for silylated 2-acetoxypropionic acid (2APA-TMS), $10.5 \mathrm{~min}$ for di-silylated lactic acid (LA-TMS) and 11.2 min for lactide. For more details, including qualitative GCMS and ${ }^{1} \mathrm{H}$ NMR data, see the ESI. $\dagger$

Unless stated otherwise, chemicals were purchased from commercial sources and used as received. Acrylic acid, 2-acetoxypropionic acid, DL-lactic acid ( $90 \%$ aqueous solution), lactide(3,6-dimethyl-1,4-dioxane-2,5-dione), $p$-toluene-sulfonic acid monohydrate, sulfanilic acid (99\%), sodium nitrite and hydrochloric acid were purchased from Sigma Aldrich. Graphene powder was purchased from Angstron Materials. Glucose, activated carbon, acetic acid and concentrated sulfuric acid (98\%) were obtained from VWR International. Amberlyst 70 was purchased from Rohm and Hass. Faujasite Y zeolite in the sodium form (nominal $\mathrm{Si} / \mathrm{Al}$ ratio of 5.1) was purchased from Zeolyst International. Sulfated zirconia was obtained from MEL Chemicals. Silica gel $60 \AA$ Å, 0.105-0.2 mm (70-150 mesh),
Nafion NR50, Ammonium heptamolybate, telluric acid, vanadyl sulfate and niobium oxalate were purchased from Alfa-Aesar.

\subsection{Procedure for acid-catalysed acetoxylation esterification}

In a typical catalytic experiment, $\mathrm{LA}_{(\mathrm{aq})}(90 \mathrm{wt} \%, 1.0 \mathrm{~g})$ and a solid acid catalyst $(0.165 \mathrm{~g}, 5.5 \mathrm{wt} \%$ of the total weight of LA and $\mathrm{AcOH})$ were added to $\mathrm{AcOH}(2.0 \mathrm{~g})$ in a three-neck round-bottom flask equipped with a reflux condenser, under vigorous stirring at $100{ }^{\circ} \mathrm{C}$ and ambient pressure. The initial molar ratio of LA to AcOH was $1: 3.3$ and no additional solvent was added. Substrate conversion and product yield were monitored by GC. Hourly samples of $124 \mu \mathrm{L}$ reaction mixture were diluted to 750 $\mu \mathrm{L}$ with dichloromethane (DCM), and reacted with $250 \mu \mathrm{L} \mathrm{N}, O$ bis(trimethylsilyl)trifluoro-acetamide (BSTFA) silylating reagent in a closed glass vial. These were placed in a water bath at $44{ }^{\circ} \mathrm{C}$ for $24 \mathrm{~h}$ to obtain full silylation of the analytes, prior to injection into the GC.

\subsection{Procedures for catalyst synthesis}

Most catalysts were prepared by modifying published procedures. Nevertheless, since small changes in the synthesis protocol can cause large effects in catalyst performance, ${ }^{29}$ we included the detailed modified procedures in the ESI. $\dagger$

Sulfonated graphene can be prepared by in situ $u^{30}$ and ex situ ${ }^{31}$ approaches. Here, we chose a two-step ex situ procedure, preparing first the diazonium salt of sulfanilic acid and then coupling it to graphene. Sulfanilic acid $(17.4 \mathrm{~g}, 0.1 \mathrm{~mol})$ was dispersed in $1 \mathrm{M} \mathrm{HCl}_{(\mathrm{aq})}(750 \mathrm{~mL})$ and maintained at $3-5{ }^{\circ} \mathrm{C}$ in an ice bath. The diazonium salt was then formed by controlled addition of $\mathrm{NaNO}_{2}(7.83 \mathrm{~g}, 0.11 \mathrm{~mol})$ in aqueous solution (80 $\mathrm{mL}$ ) for $2 \mathrm{~h}$ under magnetic stirring. The solid was filtered and washed with cold water. The diazonium salt was then dispersed in a $1: 1$ water-ethanol solution $(360 \mathrm{~mL})$ before adding graphene $(480 \mathrm{mg})$ at $3-5{ }^{\circ} \mathrm{C}$. Then, a portion of $\mathrm{H}_{3} \mathrm{PO}_{2(\mathrm{aq})}(50 \mathrm{wt} \%$, $180 \mathrm{~mL}$ ) was added. After $30 \mathrm{~min}$ stirring, another portion of $\mathrm{H}_{3} \mathrm{PO}_{2(\mathrm{aq})}(50 \mathrm{wt} \%, 180 \mathrm{~mL})$ was added and the solution was stirred for $1 \mathrm{~h}$. The sulfonated graphene was filtered, washed with abundant water and dried under vacuum.

\subsection{Procedure for catalyst re-use}

The spent catalysts were separated by centrifugation and decantation, and recycled by consecutive washing with acetone $(10 \mathrm{~mL})$ and $n$-hexane $(10 \mathrm{~mL})$. After the final washing, each catalyst was transferred in a minimal volume of acetone to a pre-weighed 3-neck round-bottom flask. It was then dried under reduced pressure at $40{ }^{\circ} \mathrm{C}$, prior to oven-drying the catalysts at $110{ }^{\circ} \mathrm{C}$ for $1 \mathrm{~h}$. Afterwards, fresh catalyst was added to re-adjust the weight to $0.165 \mathrm{~g}$.

\section{Results and discussion}

\subsection{Analytical method development}

Analysing hydroxy carboxylic acids by HPLC and GC is difficult. $^{32-37}$ On various commonly-used columns, the direct analysis of LA by HPLC and GC gives broad and erratic responses, due to strong interactions with the stationary phases. 
Furthermore, analysing the reaction mixture using ${ }^{1} \mathrm{H}$ NMR spectroscopy showed additional overlapping signals. LA is known to contain oligomers as a result of self-condensation. ${ }^{38}$ Moreover, oligomerization of LA is likely to occur at $100{ }^{\circ} \mathrm{C}$ in the presence of an acid catalyst. These oligomers give NMR signals of chemical shifts similar to LA and 2-APA. ${ }^{39}$ Thus, we could not use ${ }^{1} \mathrm{H}$ NMR spectroscopy for accurate analysis of LA, 2-APA and AA.

Addressing these issues, we developed a simple and reliable analytical method, which is suitable for use on simple silicabased capillary columns. The method is based on silylation using N,O-bis(trimethylsilyl)trifluoroacetamide (BSTFA).

Generally, alcohols are more readily silylated than carboxylic acids. However, we observed a lower susceptibility towards the silylating reagent for LA than for the other analytes. This is caused by the intramolecular hydrogen bonding that stabilizes the secondary hydroxyl group. Full conversion was obtained after $24 \mathrm{~h}$ at $44^{\circ} \mathrm{C}$. This method enables accurate GC calibration, with an $R^{2}$ value of 0.9975 for seven observations (for details and calibration graph see the ESI $\dagger$ ). ${ }^{\mathbf{4 0 - 4 2}}$

\subsection{Catalyst testing and structure-activity considerations}

Various solid acid catalysts were tested for activity in the acetoxylation reaction. These catalysts are known to be active in esterification ${ }^{\mathbf{4 3 - 4 7}}$ and hydrolysis reactions, ${ }^{48,49}$ as well as in the production of acrylic acid from glycerol and acrolein. ${ }^{50}$ Accordingly, we screened zeolites, commercial ion-exchange resins, (mixed) metal-oxides, and sulfonated carbonaceous and siliceous catalysts. All catalysts were tested using an initial LA : AcOH molar ratio of $1: 3.3$, at $100{ }^{\circ} \mathrm{C}$ under atmospheric pressure. Hourly samples were taken to determine LA conversion and 2-APA yield (Fig. 2).

A blank experiment in the absence of any catalyst, showed $<5 \%$ 2-APA yield after $5 \mathrm{~h}$. Similarly, a homogeneous control experiment using concentrated $\mathrm{H}_{2} \mathrm{SO}_{4}$ showed stabilization at chemical equilibrium at around $51 \%$ yield. In the batch reaction, water is not removed and limits higher yields. $\mathrm{H}_{2} \mathrm{SO}_{4}$ was used in $0.5 \mathrm{H}^{+}$equivalents $(22.65 \mathrm{mg}$ ), equal to the ion-exchange capacity of Amberlyst 70 at $5.5 \mathrm{wt} \%$.

Next, we evaluated the activity of Faujasite Y zeolites. We synthesized both microporous and macroporous Y zeolites, but these gave very low 2-APA yields. Though the zeolites have high acidic strength, the reaction is limited by the restricted pore size.

We then turned to commercial ion-exchange resins, known for high activity in acid catalysed reactions, and thermal and mechanical stability. These were Amberlyst 70 (macroporous sulfuric acid functionalized styrene divinylbenzene copolymer) and Nafion NR50 (mesoporous sulfonated tetrafluoroethylene based fluoropolymer-copolymer beads). Both catalysts showed high activity and selectivity to 2-APA.

Sulfated zirconia (SZ) was previously demonstrated as an active acid catalyst, with thermal stability and strong acid sites. ${ }^{\mathbf{4 4 , 4 7}}$ Two SZ catalysts were prepared by calcination at $450{ }^{\circ} \mathrm{C}$ and $650{ }^{\circ} \mathrm{C}$, but both showed low activity. The mixed phase $\mathrm{Mo}-\mathrm{V}-\mathrm{Te}-\mathrm{Nb}-\mathrm{O}$ catalyst, known for the conversion of glycerol to acrolein and $\mathrm{AA}^{, 50}$ showed only moderate activity. Control experiments using pure tellurium oxide or niobium oxide, known to be active in similar conversions, showed low activity. ${ }^{51,52}$ Moreover, when testing single phase Mo-V-Te-Nb-O materials, ${ }^{53}$ reduced activity was observed. This suggests that the active acid sites form part of the mixed phase catalyst. Sulfonated graphene showed high activity and selectivity to 2-APA. However, additional AcOH (ca. $12 \mathrm{~mL}$ ) was required to facilitate mixing, as graphene tends to absorb polar solvents. Control experiments using the same additional amount of $\mathrm{AcOH}$ with Amberlyst 70 as the catalyst showed only minor change in the reaction profile compared to the reaction under typical conditions. We can thus compare directly the results for sulfonated graphene with those for the other catalysts. Sulfonic acid functionalized silica gel gave only modest activity. Moderate results were also obtained using $p$-toluenesulfonic acid functionalized glucose (Glu-TsOH). Conversely, sulfonic acid functionalized activated carbon $\left(\mathrm{AC}-\mathrm{SO}_{3} \mathrm{H}\right)$ showed high activity and selectivity.

Though esterification is promoted by both Lewis and Brønsted acids, we think the latter plays a more important role here. Since we deliberately put $-\mathrm{SO}_{3} \mathrm{H}$ groups on carbon, their concentration is high and at a relatively low temperature of $100^{\circ} \mathrm{C}$, they are likely to have more influence than Lewis acid sites. ${ }^{54}$

The four most active catalysts were Amberlyst 70, Nafion NR50, $\mathrm{AC}_{-} \mathrm{SO}_{3} \mathrm{H}$ and sulfonated graphene. These catalysts all contain sulfonic functional groups. After $3 \mathrm{~h}$, the yields for all four were almost equivalent (see dotted vertical line in Fig. 2). The 2-APA yields at this point varied between $34-37 \%$ and selectivity to 2-APA ranged from $83-90 \%$ (Table 1 ). These results were obtained under standard reaction conditions, without further optimization. As such, optimization of the reaction conditions is expected to surpass $90 \%$ selectivity. Combining these results with the pyrolysis of 2-APA at elevated temperatures, ${ }^{6,26}$ we envisage $80-85 \%$ overall acrylic acid yield in the continuous flow reaction.

$\mathrm{NH}_{3}$ adsorption microcalorimetry was measured on the samples after activation at $100{ }^{\circ} \mathrm{C}$ for $2 \mathrm{~h}$ (Fig. 3). The results show that Amberlyst 70 (A-70) has a few stronger acid sites than the rest of the catalysts. The highest acid strength is similar for sulfonated graphene, $\mathrm{AC}-\mathrm{SO}_{3} \mathrm{H}$ and Nafion NR50. However, sulfonated graphene has the highest concentration of strong acid sites (i.e., sites with heat of adsorption $>80 \mathrm{~kJ} \mathrm{~mol}^{-1}$ ). The surface coverage values with an adsorption threshold of $80 \mathrm{~kJ}$ $\mathrm{mol}^{-1}$ were $1.22,0.52,0.11,0.91,0.90 \mathrm{mmol} \mathrm{g}^{-1}$ for sulfonated graphene, $\mathrm{AC}_{-} \mathrm{SO}_{3} \mathrm{H}$, Nafion NR-50, HY meso and Amberlyst 70, respectively. Other samples showed weaker acidities. Turnover frequencies (TOFs) were calculated by taking moles of product, divided by moles of acid sites (from microcalorimetry) over time (Table 1).

\subsection{Mechanistic studies}

Generally, esterification is promoted by both Lewis and Brønsted acids, following the Fischer esterification mechanism. ${ }^{55}$ In the acetoxylation reaction, we observed that increasing the amount of $\mathrm{AcOH}$ in the initial reaction mixture 

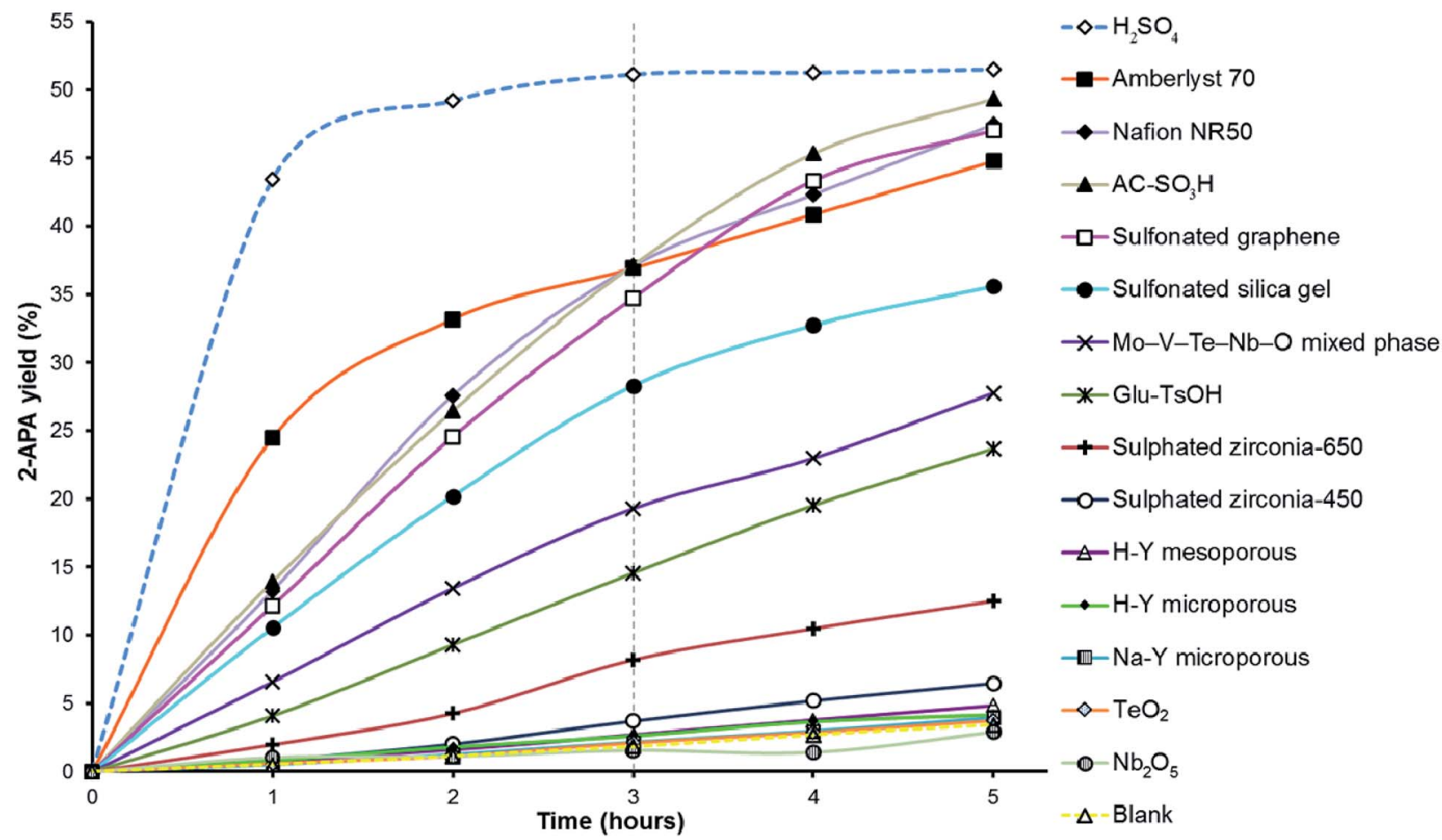

Fig. 2 Time-resolved yield of 2-APA, for various acid catalysts (colored lines are used to guide the eye; the dotted vertical line at $t=3 \mathrm{~h}$ denotes the point of comparison between the catalysts for comparing performance). Reaction conditions: LA to AcOH ratio $1: 3.3$, catalyst 5.5 wt\% of total $\mathrm{LA}$ and $\mathrm{AcOH}$ amount, $T=100^{\circ} \mathrm{C}$.

Table 1 Conversion $(X)$, selectivity $(S)$, yield $(Y)$ and turnover frequency (TOF) for acetoxylation of LA to 2-APA, for the four most active catalysts $^{a}$

\begin{tabular}{|c|c|c|c|c|}
\hline & $X_{\mathrm{LA}}(\%)$ & $S_{2-\mathrm{APA}}(\%)$ & $Y_{2-\mathrm{APA}}(\%)$ & TOF $\left(\mathrm{h}^{-1}\right)$ \\
\hline Amberlyst 70 & 42 & 87 & 37 & 8 \\
\hline Nafion NR50 & 41 & 90 & 37 & 70 \\
\hline $\mathrm{AC}_{-} \mathrm{SO}_{3} \mathrm{H}$ & 44 & 84 & 37 & 15 \\
\hline $\begin{array}{l}\text { Sulfonated } \\
\text { graphene }^{b}\end{array}$ & 42 & 83 & 34 & 6 \\
\hline
\end{tabular}

${ }^{a}$ Reaction conditions: LA to AcOH ratio $1: 3.3$, catalyst $5.5 \mathrm{wt} \%$ of total LA and AcOH amount, $T=100^{\circ} \mathrm{C}$. Samples taken after 3 h. ${ }^{b}$ Additional $\mathrm{AcOH}$ was required to obtain a mixable slurry.

leads to lower conversion and higher selectivity. Accordingly, the reaction conditions were maintained uniform throughout (LA : AcOH ratio $1: 3.3 ; 100{ }^{\circ} \mathrm{C}$ ), to compare catalytic activities of the various catalysts.

The influence of LA oligomerization was studied by an induction experiment (Fig. 4, empty circles), where we first ran the reaction with no catalyst for $5 \mathrm{~h}$, and then added Amberlyst 70. This gave higher 2-APA yields ( $c f$. the standard conditions, Fig. 4, full circles), suggesting that the induction period promotes LA conversion to oligomers, which are more reactive. In the industrial synthesis of polylactic acid, LA is first converted to lactide, which is more active in ring-opening polymerization. ${ }^{56,57}$ This is a two-step process - the LA is first condensed by removing water above $200^{\circ} \mathrm{C}$. Then, the dimer is

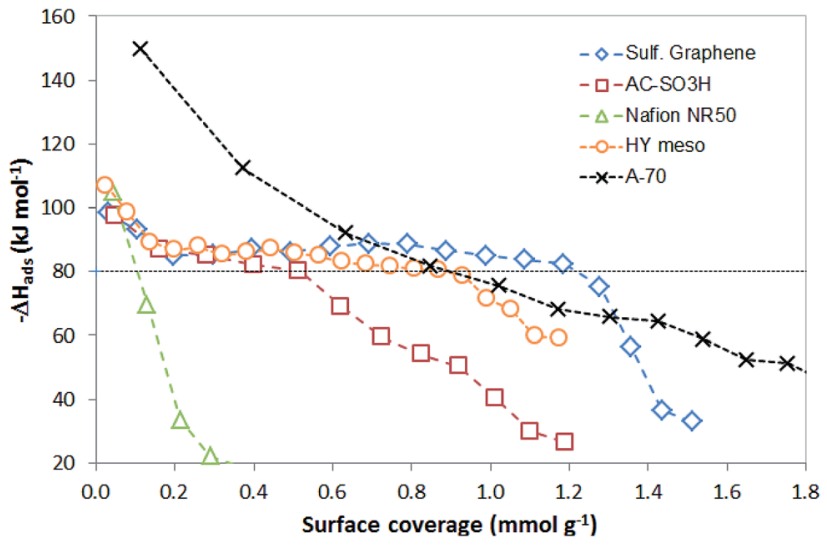

Fig. $3 \mathrm{NH}_{3}$ adsorption microcalorimetry results for various samples. The acid strength is proportional to the heat of adsorption, and the surface coverage indicates the concentration of acid sites.

cyclized, either thermally, or in the presence of an acid catalyst. However, when we used lactide as the substrate for comparison, we saw lower yields of 2-APA (Fig. 4, square symbols).

\subsection{Catalyst recycling studies}

We then carried out recycling studies for the four most active solid acid catalysts. The influence of different washing solvents for catalyst regeneration was tested using $\mathrm{H}_{2} \mathrm{O}$, ethanol, acetone, toluene and $n$-hexane. For the carbonaceous catalysts, washing only with polar solvents caused a dramatic loss of 


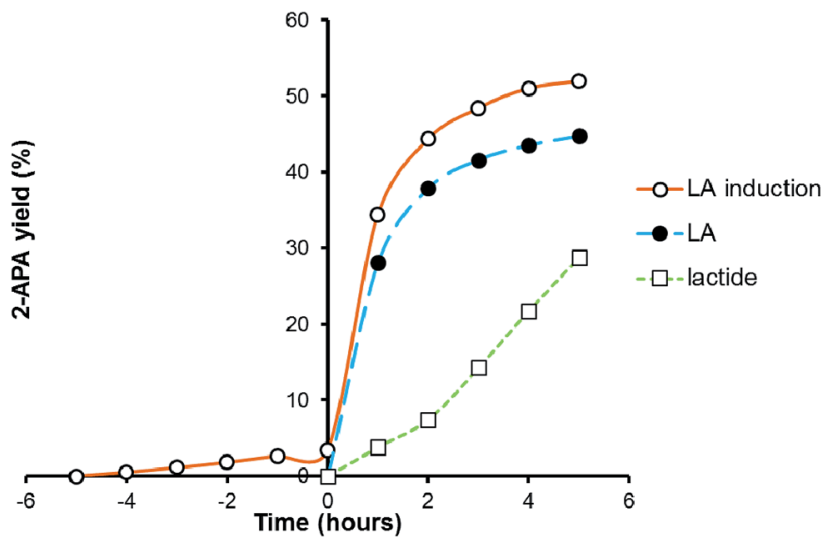

Fig. 4 Time-resolved yield of 2-APA. Reaction conditions: LA/lactide to $\mathrm{AcOH}$ ratio $1: 3.3,5.5 \mathrm{wt} \%$ (w.r.t. the total amount of $\mathrm{LA}$ and $\mathrm{AcOH}$ ) Amberlyst $70, T=100^{\circ} \mathrm{C}$. Negative time denotes the induction period in absence of any catalyst, before introducing Amberlyst 70 at $t=0$.

activity, while non-polar solvents gave only a slight decrease. ${ }^{58}$ For the ion-exchange resins, varying the washing solvent did not influence the catalytic activity. Polar solvents can remove organic deposits, as well as weakly bonded acid groups. Nonpolar solvents may remove carbonaceous residues. Optimal recycling results were obtained with subsequent acetone and $n$ hexane washing and consecutive drying.

After regeneration each catalyst, fresh catalyst was added to maintain the standard weight. The activity of the recycled catalysts was re-calculated, accounting for the amount of fresh catalyst added per cycle. Fig. 5 shows the results after reacting $3 \mathrm{~h}$ (note that these trends were also observed after $1 \mathrm{~h}$ ). The sulfonated graphene and $\mathrm{AC}-\mathrm{SO}_{3} \mathrm{H}$ catalysts were less active after each recycling step. The activity of the Nafion NR50 catalyst decreased after the first and second recycling steps, but stabilized in further recycling. The Amberlyst 70 catalyst was stable and remarkably showed slightly increased 2-APA yield. This may be due to a more open polymer structure as a result of resin swelling during the washing procedure.

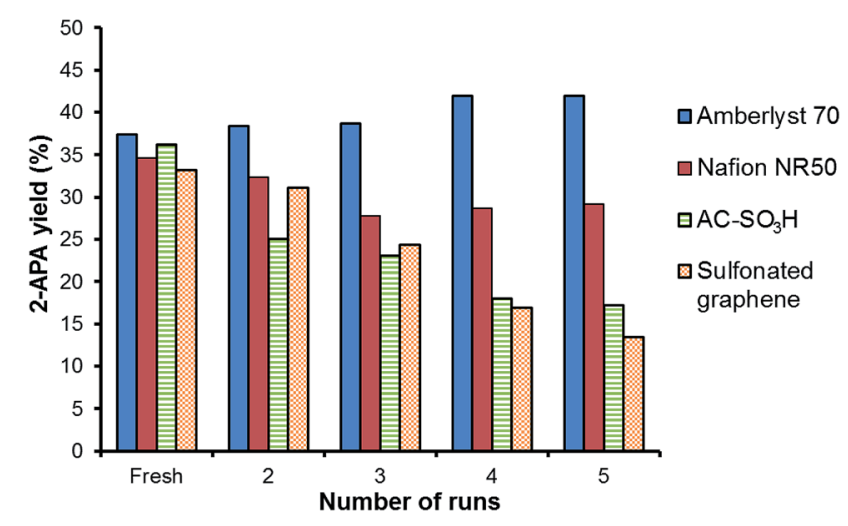

Fig. 5 Yield of 2-APA over multiple recycling steps. Samples taken after $3 \mathrm{~h}$ (cf. dotted vertical line in Fig. 2). Reaction conditions: $\mathrm{LA}$ : $\mathrm{AcOH}$ ratio 1.0 : 3.3; catalyst $5.5 \mathrm{wt} \%$ (w.r.t. the total amount of $L A$ and $\mathrm{AcOH}) ; 100{ }^{\circ} \mathrm{C}$.
We envisage two general pathways for the deactivation of these sulfonic catalysts. The first is blocking of the active sites, by fouling or collapse of the support. The second is leaching of the acid groups, resulting in permanent loss of the catalytic activity. In fact, for graphene it was demonstrated that strong absorption of chemicals occurs in parallel with the covalent diazotization, even using long washing procedures. ${ }^{55}$

Elemental analysis of the fresh and spent Amberlyst 70 samples shows 99\% retention of sulfonic groups. This explains the maintained activity during recycling. Conversely, the spent sulfonated graphene catalyst lost $50 \%$ of its sulfur. It is difficult to say the reason, however, it was observed previously that reaction and treatment conditions influence the recyclability of the resin catalysts. ${ }^{59}$ Also, the leaching of $-\mathrm{SO}_{3} \mathrm{H}$ groups is reaction specific. For example, we observed leaching from sulfonated silica in hemicellulose depolymerisation, ${ }^{49}$ while there was no leaching from the same type of catalyst in conversion of furfuryl alcohol into butyl levulinate. ${ }^{60}$

\section{Conclusions}

The solid-catalysed acetoxylation of lactic acid is a selective route to 2-acetoxypropionic acid. Subsequent pyrolysis can give acrylic acid, whilst simultaneously regenerating acetic acid, which is also the solvent in the first step. Yields of up to $85 \%$ acrylic acid are expected when both steps are combined. Various sulfonated ion-exchange resins and carbon-based catalysts show high activity and selectivity, in reacting a $90 \mathrm{wt} \%$ lactic acid solution. The recycling studies demonstrate that the carbon-based catalysts lose their activity due to leaching of the sulfonic groups, while the activity of the ion-exchange resins stabilizes after several runs. These resins are good acetoxylation catalysts, and make this synthetic route a viable option for biorenewable production of acrylic acid.

\section{References}

1 T. Willke and K. D. Vorlop, Appl. Microbiol. Biotechnol., 2004, 66, 131-142.

2 F. Budde, U.-H. Felcht and H. Frankemölle, Value Creation, Wiley-VCH, Weinheim, 2005.

3 Z. Strassberger, S. Tanase and G. Rothenberg, RSC Adv., 2014, 4, 25310-25318.

4 K. Weissermel and H.-J. Arpe, Industrial Organic Chemistry, Wiley-VCH, Weinheim, 2003.

5 IHS Chemicals, Acrylic Acid, Acrylate Esters and Superabsorbent Polymers, http://www.ihs.com/products/ chemical/planning/ceh/acrylic-acid-acrylate-esters.aspx, accessed 04-04-2014.

6 H. A. Wittcoff, B. G. Reuben and J. S. Plotkin, Industrial Organic Chemicals, Wiley-VCH, Weinheim, 2012.

7 Platts, Global Propylene Price Index, http://www.platts.com/ news-feature/2014/petrochemicals/pgpi/propylene, accessed 04-04-2014.

8 ICIS, European propylene, butadiene, prices rise above ethylene, 2010, http://www.icis.com/blogs/chemicals-and-the-economy/ 
2010/03/european-propylene-and-butadiene-prices-rise-aboveethylene/, accessed 27-11-2014.

9 A. J. Straathof, S. Sie, T. Franco and L. M. Wielen, Appl. Microbiol. Biotechnol., 2005, 67, 727-734.

10 M. Dusselier, P. Van Wouwe, A. Dewaele, E. Makshina and B. F. Sels, Energy Environ. Sci., 2013, 6, 1415.

11 Y.-J. Wee, J.-N. Kim and H.-W. Ryu, Food Technol. Biotechnol., 2006, 44, 163-172.

12 E. V. Ramos-Fernandez, N. J. Geels, N. R. Shiju and G. Rothenberg, Green Chem., 2014, 16, 3358-3363.

13 F. A. Castillo Martinez, E. M. Balciunas, J. M. Salgado, J. M. Domínguez González, A. Converti and R. P. D. S. Oliveira, Trends Food Sci. Technol., 2013, 30, 70-83. 14 J. Zhang, J. Lin and P. Cen, Can. J. Chem. Eng., 2008, 86, 1047-1053.

15 R. A. Sawicki, US Pat., 1988/4729978, 1988.

16 C. Paparizos, S. R. Dolhyj and W. G. Shaw, US Pat., 1988/ 4786756, 1988.

17 C. T. Lira and P. J. McCrackin, Ind. Eng. Chem. Res., 1993, 32, 2608-2613.

18 R. E. Holmen, US Pat., 1958/2859240, 1958.

19 P. Sun, D. Yu, K. Fu, M. Gu, Y. Wang, H. Huang and H. Ying, Catal. Commun., 2009, 10, 1345-1349.

20 H. Wang, D. Yu, P. Sun, J. Yan, Y. Wang and H. Huang, Catal. Commun., 2008, 9, 1799-1803.

21 J. Zhang, Y. Zhao, M. Pan, X. Feng, W. Ji and C.-T. Au, ACS Catal., 2011, 1, 32-41.

22 V. C. Ghantani, S. T. Lomate, M. K. Dongare and S. B. Umbarkar, Green Chem., 2013, 15, 1211.

23 V. C. Ghantani, M. K. Dongare and S. B. Umbarkar, RSC Adv., 2014, 4, 33319-33326.

24 T. M. Aida, A. Ikarashi, Y. Saito, M. Watanabe, R. L. Smith and K. Arai, J. Supercrit. Fluids, 2009, 50, 257-264.

25 W. S. L. Mok, M. J. Antal and M. Jones, J. Org. Chem., 1989, 54, 4596-4602.

26 O. S. Fruchey, T. A. Malisezewski and J. E. Sawyer, WO 2013/ 036389, 2013.

27 M. A. Lilga, T. A. Werpy and J. E. Holladay, US Pat., 2006/ 6992209, 2006.

28 E.-J. Ras, S. Maisuls, P. Haesakkers, G.-J. Gruter and G. Rothenberg, Adv. Synth. Catal., 2009, 351, 3175-3185.

29 E.-J. Ras and G. Rothenberg, RSC Adv., 2014, 4, 5963-5974.

30 E. Coşkun, E. A. Zaragoza-Contreras and H. J. Salavagione, Carbon, 2012, 50, 2235-2243.

31 J. Ji, G. Zhang, H. Chen, S. Wang, G. zhang, F. Zhang and X. Fan, Chem. Sci., 2011, 2, 484-487.

32 K. Molever, J. Cosmet. Sci., 2002, 53, 121-126.

33 M. Staniforth, M. O'Hanlon and T. M. Khong, J. Chromatogr. A, 1999, 833, 195-208.

34 K. R. Kim, M. K. Hahn, A. Zlatkis, E. C. Horning and B. S. Middleditch, J. Chromatogr. A, 1989, 468, 289-301.
35 P. G. Brotz and D. M. Schaefer, J. Microbiol. Methods, 1987, 6, 139-144.

36 D. L. Schooley, F. M. Kubiak and J. V. Evans, J. Chromatogr. Sci., 1985, 23, 385-390.

37 P. S. Nassos, J. E. Schade, A. D. King and A. E. Stafford, J. Food Sci., 1984, 49, 671-674.

38 D. T. Vu, A. K. Kolah, N. S. Asthana, L. Peereboom, C. T. Lira and D. J. Miller, Fluid Phase Equilib., 2005, 236, 125-135.

39 S. Konishi, T. Yokoi, B. Ochiai and T. Endo, Polym. Bull., 2009, 64, 435-443.

40 K. Y. Tserng, C. A. Gilfillan and S. C. Kalhan, Anal. Chem., 1984, 56, 517-523.

41 F. Khabbaz, S. Karlsson and A.-C. Albertsson, J. Appl. Polym. Sci., 2000, 78, 2369-2378.

42 A. Kamal, J. Microbiol. Biotechnol., 2011, 21, 37-42.

43 B. Zhang, J. Ren, X. Liu, Y. Guo, Y. Guo, G. Lu and Y. Wang, Catal. Commun., 2010, 11, 629-632.

44 A. A. Kiss, A. C. Dimian and G. Rothenberg, Adv. Synth. Catal., 2006, 348, 75-81.

45 D. Kusdiana and S. Saka, Bioresour. Technol., 2004, 91, 289295.

46 K. Komers, J. Machek and R. Stloukal, Eur. J. Lipid Sci. Technol., 2001, 103, 359-362.

47 K. Saravanan, B. Tyagi and H. C. Bajaj, Catal. Sci. Technol., 2012, 2, 2512.

48 J. Ji, G. Zhang, H. Chen, S. Wang, G. Zhang, F. Zhang and X. Fan, Chem. Sci., 2011, 2, 484.

49 P. Demma Cara, M. Pagliaro, A. Elmekawy, D. R. Brown, P. Verschuren, N. R. Shiju and G. Rothenberg, Catal. Sci. Technol., 2013, 3, 2057-2061.

50 J. Deleplanque, J.-L. Dubois, J.-F. Devaux and W. Ueda, Catal. Today, 2010, 157, 351-358.

51 W. D. Pyrz, D. A. Blom, N. R. Shiju, V. V. Guliants, T. Vogt and D. J. Buttrey, Catal. Today, 2009, 142, 320-328.

52 N. R. Shiju, D. R. Brown, K. Wilson and G. Rothenberg, Top. Catal., 2010, 53, 1217-1223.

53 N. Watanabe and W. Ueda, Ind. Eng. Chem. Res., 2006, 45, 607-614.

54 K. Wilson, D. J. Adams, G. Rothenberg and J. H. Clark, J. Mol. Catal. A: Chem., 2000, 159, 309-314.

55 M. Castelaín, P. S. Shuttleworth, C. Marco, G. Ellis and H. J. Salavagione, Phys. Chem. Chem. Phys., 2013, 15, 16806.

56 D. Garlotta, J. Polym. Environ., 2001, 9, 63-84.

57 R. Mehta, V. Kumar, H. Bhunia and S. N. Upadhyay, J. Macromol. Sci., Polym. Rev., 2005, 45, 325-349.

58 A. Goifman, J. Gun, V. Gitis, A. Kamyshny Jr, O. Lev, J. Donner, H. Bornick and E. Worch, Appl. Catal., B, 2004, 54, 225-235.

59 E. Andrijanto, E. A. Dawson and D. R. Brown, Appl. Catal., B, 2012, 115-116, 261-268.

60 P. Demma Cara, R. Ciriminna, N. R. Shiju, G. Rothenberg and M. Pagliaro, ChemSusChem, 2014, 7, 835-840. 